\title{
Solar-Powered Direct-Current Loads in Small Buildings
}

\author{
Prakash Sarnobat ${ }^{1,2}$ and Simon Lannon ${ }^{1}$ \\ 1. Welsh School of Architecture, Bute Building, Cardiff CF10 3NB, UK \\ 2. A Flows, 53 Llwynygrant Road, Penylan, Cardiff CF23 9HL, UK
}

Received: January 22, 2014 / Accepted: August 07, 2015 / Published: September 30, 2015.

\begin{abstract}
Traditional light bulbs (e.g., incandescent, fluorescent) use too much electricity, convert very little energy into light of sufficient quality and in their production use toxic contaminants. During the last few years, a new type of light source, LED (light emitting diode) bulb, has gained increasing popularity and its costs are set to plunge even further. LED bulbs offer many advantages over traditional sources, and they can be used as a direct replacement to existing lighting. This paper will use a spreadsheet-based analysis with hourly solar data supplied by Ecotect to show that, the efficiency of LED installations can be increased when used in conjunction with photovoltaic modules, as the two generate (and use) DC (direct-current) electricity, thereby eliminating intermediate-level losses in the electronic circuitry. If a storage battery is included, the solar panels generate electricity during the times when the occupants are not necessarily using the lighting, but the stored electricity can be used to power the lighting when the energy is required. The latest results demonstrate that, a slight reduction in the required floor area to be lit allows the solar-battery-LED system to be implemented in small buildings using a storage battery size that is within the range of present commercial devices.
\end{abstract}

Key words: Energy efficiency, photovoltaics, LED lighting, simulation.

\section{Introduction and Background}

Energy efficiency has been taken on an increasingly important role, given the threat of dwindling resources and climate change. Buildings are one of the largest users of energy in the western world, and there is plenty of scope for reducing its use. Lighting contributes around $20 \%$ of the energy use, and the potential exists to half this figure. A technology that has matured during the last few years is semiconductor LED (light emitting diodes), which use DC (direct current) electricity for their operation. Another technology that has also gained popularity in the built environment in recent years is semiconductor PV (photovoltaics), which generates DC electricity directly from sunlight. The two technologies can be used in combination to potentially produce an efficient and sustainable interior lighting system.

Traditional lighting systems used incandescent (i.e.,

Corresponding author: Prakash Sarnobat, consulting engineer, research field: building physics. E-mail: psarnobat@gmail.com. filament) light bulbs. Although cheap to purchase, and possessing a good light quality which mimics natural daylight, less than $5 \%$ of the electrical power is converted into light with the remainder being emitted as heat into the room. This means energy is wasted both in powering the bulb, and in the building cooling systems to extract the emitted heat from the room.

A few decades ago, fluorescent lighting came on the market: It is more efficient than incandescent lighting (around 10\%), but produces a rather artificial light output profile which can cause psychological discomfort to occupants, and also produces toxic substances (e.g., mercury) making their safe disposal quite problematic.

LEDs were first invented in the 1960s and were mainly used in lighting applications for electronic equipment, due to them emitting a particular colour, and due to emitting light in a quite narrow beam (less than 30 degrees). Compared to old light sources, they have a much longer lifetime, typically 25 years as opposed to 5 years CFL (compact fluorescent lights) 
and 2 years (incandescent). The last decade has seen unprecedented improvements, LEDs can generate warm-white light with a spectrum that is almost as good as daylight, sophisticated optics that allow light emission at both wide and narrow beam angles have been developed, and efficiencies are now at least as high as the corresponding CFL.

The big breakthrough came in $2008[1,2]$ when it was shown that, it is possible to take advantage of the processes in the manufacturing of computer chips to reduce the cost of producing LEDs by up to tenfold, the typical LED now costs around three times as much as its CFL counterpart but its physical performance is at least as good as; if not better. According to Shailesh [3], the operating costs over 25 years can be reduced by $80 \%$ if the constant use of fluorescent lamps is replaced by LED lighting combined with sensors for daylight and occupancy levels. The one outstanding issue that remains is thermal management: Although less heat is produced than in other light sources, if it is not extracted away from the device then the light output will degrade [4], or even worse damage will occur. Both Parry [5] and Narendran [6] discuss how to address the issue using computational fluid dynamics.

Even a single luminaire can have its spectral output programmed to be time-varying such that it can mimic the behaviour of daylight over a full day [7]. Work is currently underway to develop "Wi-fi" LED lighting, where it is hoped that, information can be transmitted using optical photons as opposed to the current method using wireless (non-visible) photons. No doubt, there will be other innovative uses for LED lighting.

PV technology has traditionally been the domain of remote, off-grid systems, due to its efficiency losses when implemented in the form of a centralized, large-scale power generating plant. Improvements in performance and cost have made PV panels increasingly popular in being integrated into the building architecture, especially if they are roof-mounted. Most PV are made out of single-junction crystalline silicon, and as of 2012, the average efficiency of $\mathrm{PV}$ modules is around $15 \%$ with a typical cost of around $£ 2,000$ per installed $\mathrm{kW}$, and this is set to improve even further. One must be careful not to confuse (industrially-manufactured) module efficiency with lab efficiency, where the latter can be a lot higher. Single-juction cells have an upper limit on the efficiency of $30 \%$ due to the Shockley-Quessier limit which has its origins in statistical thermodynamics. The development of multi-junction cells is underway, and lab efficiencies of $40 \%$ have been achieved, but module efficiencies are less than $10 \%$ and costs are much higher than silicon.

Solar electricity is DC, yet many of the appliances in a building are AC (alternating current), and an inverter is needed to make the required conversion, this will result in significant efficiency losses. Nevertheless, Liu [8, 9] has performed a system optimization for using PV and battery to power residential buildings in Queensland, and finds that, $6 \mathrm{~kW}$ roof-mounted panels with an angle of 20-25 degrees can provide nearly two-thirds of the electricity requirements.

Given that LED lighting is also DC, this makes it ideal to use PV panels to power LED luminaires for interior room lighting, there are efficiency savings on not involving the use of an inverter. However, sunlight is not constant, and the lighting energy is sometimes needed when the sun does not shine, for a residential building, energy is generated during the day when the occupants are out, and it is needed during the evening when the occupants have returned. Clearly, some sort of storage is required in the form of a suitable battery. During the winter months sunlight is minimal and electricity must be drawn from the grid, and correspondingly during the summer months more electricity will be produced than is needed for the building; the excess is sold to the grid at an externally determined rate. According to tests by Sastry [10], the 
combined PV and battery energy sizing can be reduced by up to $50 \%$ if $\mathrm{PV}$ modules are used to power LED lamps rather than CFL lamps. Note that, although an inverter is not needed when PV is used to directly power LEDs, it is needed when use is made of the grid. Having said that, Boeke, et. al. [11] show that, using PV to power LED lights still results in electricity savings of $15 \%$ compared to using $\mathrm{AC}$ mains alone. Moreover, Boeke, et. al. [12] then state that, by having an appropriate local DC electricity grid for rural businesses, the PV and battery costs (and the overall economic costs of PV-powered systems) can be significantly reduced. Patel [13] discusses a systematic procedure for calculating the overall efficiencies when various types of components are involved, and pode discusses strategies for encouraging uptake of PV-LED systems [14].

The lifetime of the battery is determined by the number of charging-discharging cycles it can undergo when discharging to $80 \%$ of the full capacity - this is said to be a "deep cycle". The lifetime itself will depend on some key factors, including the discharge depth, rate of discharge and temperature. Shallow cycling of batteries is used for large discharge rates in order to minimize the heat generated within the battery and prolong its lifetime. In addition, the "cycle efficiency" is the percentage energy hysteresis between charging and discharging. Leadbetter and Swan [15] give a broad and up-to-date overview of the comparison of different battery types that are suitable for renewable energy systems: lead-acid ( $\mathrm{Pb}-\mathrm{A})$, sodium-sulphur (Na-S), vanadium-redox (VRB), and lithium-ion (Li-Ion). Nickel-based batteries are being gradually phased out due to cost and environmental concerns. At the present time, the most common is lead-acid, as this is a mature technology which has low upfront costs, however, it has a limited lifetime. sodium-sulphur has both low cost and long lifetime, however, heat must be provided to keep the sodium in its liquid state (costing energy) during times when the battery is not operating, else a self-discharge of $20 \%$ per day occurs. This makes it unsuitable for PV systems, as the battery requirement tends to be seasonal. Vanadium redox has a very long lifetime, but needs to operate within a narrow temperature range of $10-35^{\circ} \mathrm{C}$, requiring local climate control (and the resulting additional energy), and a large storage space is required. Lithium-ion batteries had their origins in microelectronic devices, but recently their capabilities have been scaled up to larger systems. Of the four battery types, they are the only ones that possess a cycle efficiency of close to $100 \%$. And unlike their lead-acid counterparts, they last twice as long, and do not require regular maintenance. At the present time the initial costs are high, around 40 $\mathrm{p} / \mathrm{kWh}$ this is expected to drop below $30 \mathrm{p} / \mathrm{kWh}$ in a few years, making lithium-ion batteries competitive [16]. AllCell Technologies [17] give a worked example comparing lead-acid and lithium-ion technologies, demonstrating that the latter are already better suited to hot climates. Following [15], the relevant properties of the four battery types are summarized in where for lead-acid and lithium-ion batteries the "energy cell" figures have been chosen as opposed to the "power cell" figures, as we want to avoid using large currents for LED lighting.

Table 1 Comparison of the various battery types.

\begin{tabular}{lllll}
\hline & Pb-A & Li-Ion & Na-S & VRB \\
\hline Cycle life & $200-1,800$ & $3,000+$ & 4,500 & $10,000+$ \\
Energy density (Wh/L) & $50-80$ & $200-500$ & $150-250$ & $16-33$ \\
Daily self-discharge (\%) & $<0.5$ & $0.1-0.3$ & 20 & Negligible \\
Cycle efficiency (\%) & $63-90$ & $80-98$ & $75-90$ & $75-80$ \\
Capital cost (US\$ per kWh) & $200-600$ & $600-1,200$ & 350 & $150-1,000$ \\
\hline
\end{tabular}


As the lighting load will vary during the year due to daylight, it is assumed that, a suitable MPPT (maximum power point tracking) algorithm is in operation (Ref. [18] and references contained therein). An innovative method of increasing battery charging capacity by nearly $80 \%$ has been suggested by Huang [19], which states that instead of using MPPT for the PV in relation to the load, operate at near maximum power point while using pulse width modulation to control discharging of the battery. This also has the advantage of reducing the MPPT conversion loss when an undersized load is used.

It has been suggested that, using solar-angle tracking for PV systems can increase power output by up to $50 \%$ [20]. Although this is not considered in the present work, it is nevertheless being considered by the authors in ongoing work.

An earlier investigation by the authors [21] of the effectiveness of using wall-mounted PV panels to power LED lighting systems for large, multi-level office buildings showed that the most important system parameters were the PV cost and efficiency, number of desk lights, feed-in tariffs and cost of the old lighting system being replaced. This article focuses on small buildings, especially residential, with PV panels mounted on a south-facing roof as opposed to the walls. Sometimes the roof has a complex shape, constraining the layout of the PV panels, and one cannot really associate any individual panel(s) as belonging to any particular room. In this case the building must be analysed as a whole. For simple roofs possessing a high degree of symmetry, then one can imagine dividing the roof space (and its PV panels) as "belonging to" a particular floor of a two-level building. Indeed, this decomposition can be applied to some terraced houses that have been converted into separate apartments, each occupying one floor. Indeed, the simulation data was obtained for a detached house, but one could also imagine that it equivalently forms part of a row of terraced houses.

There are several tools on the market for both PV and lighting analysis, the most popular being Homer, PV-Sys and TRNSYS (TRaNsient SYStems) for PV (which can also include the battery analysis), and Dialux, Ecotect, and IES-VE (integrated environmental services-virtual environment) for lighting (to a lesser extent IES-VE can also do PV analysis, but not batteries). At present, there is no single tool that can perform PV, battery, and lighting analysis all in one place. RetScreen is an all-round tool in this regard, but it only does monthly analysis. The spreadsheet developed for this work is intended to perform all three types of analyses based on hourly data. Work is underway to generalize the tool to also deal with hourly data obtained from thermal modelling.

The aim of this work is to give a first indication of the energy requirements, such that key decisions on several "what-if" scenarios can be made during early-stage design. Once the optimum building configuration has been chosen, then detailed analysis can proceed as usual, indeed, the resulting value of the lighting energy from this can be input into the spreadsheet used in this analysis to more accurately determine the PV area and battery capacity. It is hoped that, this shall become a useful tool for architects, engineers and building managers alike. Further, the analysis is extrapolated from the present day to consider long-term horizons up to 2050, where we show that, the payback period will be a third of what it is today. Although this work focuses on the United Kingdom, the fundamental methods can be applied anywhere in the world.

\section{Methodology}

The system under consideration is a Detached house that consists of PV panels on its south-facing roof (Fig. 1), and its interior consisting of a battery and the DC loads, in this case the LED lighting.

Both commercial software and excel spreadsheet-based analyses were used. Annual hourly solar radiation data for Bristol was obtained from EcoTect, and converted into watt-hours (Wh) for PV 
panels. Based on peak values of this data, the PV system was sized at $1.5 \mathrm{~kW}$.

The battery capacity was sized in relation to the daily excess of the load requirements versus the PV input, averaged over the year, and this was termed the daily deficit. In sizing the battery, a margin of 50\% spare capacity was allowed to account for various losses. Its state of charge was determined by the difference between energy input from the PV, and energy extracted by the loads, including a battery self-discharge of approximately $2 \%$ per month. As the hourly self-discharge is relatively small, of the order of a fraction of a Wh, this behaviour can be assumed as linear.

The state of charge on the battery is determined by the difference between the PV input and its use by the loads. If this difference is greater than the maximum capacity of the battery, then any excess is fed to the grid. Conversely, if the PV input is insufficient to power the loads, then the (hourly) deficit will be taken from the grid. An hourly profile for the room lighting was specified to be on between 7 a.m. and 9 a.m., and from 6 p.m. to 11 p.m., with the lights off outside these hours, daylight was not considered. Based on this lighting schedule, and on the PV input, annual hourly values for the state of charge, deficit and excess were calculated. From these quantities, the monthly values over the year of highest and lowest excess/deficit are obtained, and whether or not there is an annual net use of the grid. The price for using the grid is $12 \mathrm{p} / \mathrm{kWh}$.

Excess energy fed to the grid will result in a price being paid by the government to the building owner, called a FIT (feed-in tariff). The FIT gradually decreases every year, and as of early 2013 , it is 16 pence per $\mathrm{kWh}$ for generation (irrespective of whether or not it is used locally) plus an additional export tariff of $4.5 \mathrm{p} / \mathrm{kWh}$. This payment, in addition to the savings on the electricity bill prior to installation, can be used to offset the initial cost. The time it takes for this to happen is called the payback period, and it can

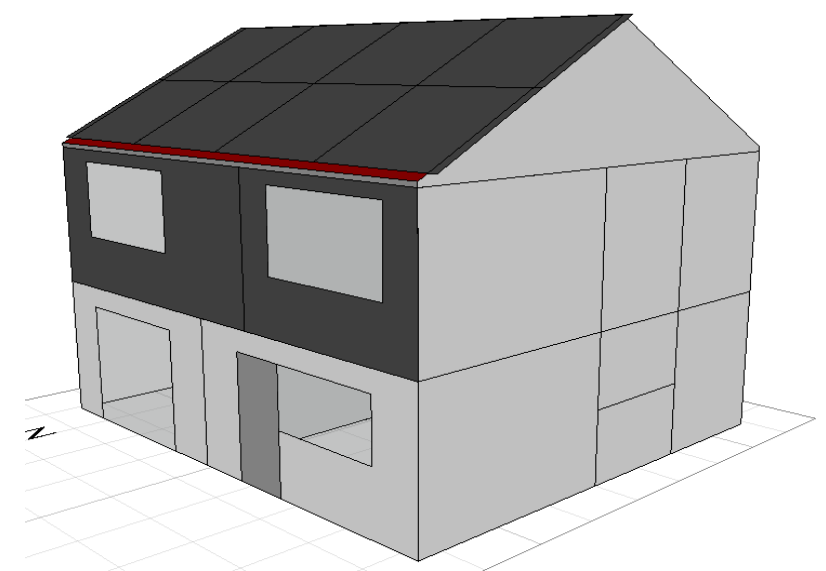

Fig. 1 Cross section of the house, with PV panels mounted on the south-facing roof.

depend on a number of factors. When describing the efficiency of a luminaire, one must only consider the wavelengths (and corresponding light energies) that are sensitive to human vision, and not anything outside this range. One therefore talks of lighting power in lumens, which, approximately speaking could be regarded as "optical watts", and the number of lumens reaching a square metre of the working plane (which is an imaginary surface one metre above the floor) is termed lux. The ratio of lighting power to electrical power is termed luminous efficacy, or just "efficacy".

The lumen method regards the light from a luminaire as corresponding to a mathematically equivalent source that is uniformly distributed over a certain area of the ceiling, and being emitted vertically downwards over that same area of the working plane. If the luminaire has power $P$ and luminous efficacy $\eta$, then, the total number of luminaires $N$ that are required to produce a given lux level $E$ at the working plane of area $A$ is:

$$
N=\frac{E A}{\eta P M U}
$$

where, $M$ is the maintenance factor, and $U$ is the utilization factor. $M$ accounts for the degradation of the luminaire over time (e.g., due to dirt), and $U$ describes the fraction of light from the luminaire that actually reaches the working plane. 
The key determinant of the economic viability of the whole system is its lifetime costs, and in particular, the payback period taking into account inflation interest rates. The sum of the annual payments forms a geometric series, which can be evaluated in closed form. For a given capital cost of the PV-battery-LED system, annual FIT $(G)$, market discount rate for investment $(d \%)$, annual rate of electricity price inflation $(i \%)$, and annual operating costs of the old lighting system $(L)$, the payback period $(T)$ in years is given by:

$$
T=\frac{\ln \left[1+\frac{C(i-d)}{(G+L)}\right]}{\ln \left[\frac{1+i}{1+d}\right]}
$$

As the battery lifetime (12.5 years) is shorter than the PV and LED lifetime (25 years), more than one battery will be used. The cost of subsequent future batteries must be discounted to the present value using the following NPV (net present value) factor, where $\tau$ is the number of years before the replacement battery is installed:

$$
N P V=\frac{1}{(1+d)^{\tau}}
$$

Given the current economic climate, it seems reasonable to assume that, a typical value of $d$ is $3 \%$, and a typical value of $i$ is $5 \%$.

For the old lighting system, the capital cost of replacement luminaires must also be adjusted by using an appropriate NPV factor. This cost can be accounted for in the payback period by subtracting it from the upfront capital cost $(C)$, thus creating a "modified upfront capital cost". The manufacturing and disposal cost are not considered here, as this is not the responsibility of the building owner, else it is implicit in the capital costs.

It is more instructive to analyse the building as consisting of two separate floors, each using half the space available for PV generation on the south-facing roof. The question that we ask is "to what extent can half the roof power one floor?".
Although this particular house is a detached family home, it can equivalently be regarded as consisting of a terraced house being sub-divided into two separate apartments. Moreover, if each apartment consists of one or two people, then not all of the rooms on each floor will be occupied. It makes sense to only keep the lights on in the occupied room(s), where sensors are able to detect occupancy, with the corridor light always switched on for safety reasons. It is assumed that, this configuration amounts to $50 \%$ of the apartment's floor area being lit (in reality, suitable lighting controls will be required with carefully timed dimming, so that, the on-off switching does not cause visual discomfort to the occupants), and a comparative analysis was done for $100 \%$ of the floor area being lit (no sensors) against $50 \%$ of the floor area being lit (with sensors).

The loads will depend on the type of luminaire we use, but a typical luminous efficacy for warm white LEDs (as of 2012) is $60 \mathrm{~lm} / \mathrm{W}$, and this is set to improve even further. For a house with $7.2 \mathrm{~m} \times 8.2 \mathrm{~m}$ floor area and $2.4 \mathrm{~m}$ room height (implying $K$-factor and utilization factor of 1.17 and 0.9 , respectively), one can use the lumen method to show that, if the working plane requirement of 150 lux is to be satisfied using $7 \mathrm{~W}$ ceiling-mounted luminaires, 14 of these luminaires are required resulting in a total power requirement of $102.5 \mathrm{~W}$. The old lighting system that is being replaced is a mains-powered CFL based system of efficacy $60 \mathrm{~lm} / \mathrm{W}$, lifetime of 5 years, and capital cost of $£ 2$ per 1,000 lumens.

The area of the south-facing part of the roof is $34 \mathrm{~m}^{2}$, and the whole of this area is to be fitted with $\mathrm{PV}$ panels, giving $17 \mathrm{~m}^{2}$ of $\mathrm{PV}$ panels to provide power to each floor. It was assumed that, there were no exterior obstructions to create shadowing. The PV efficiency is assumed to be $15 \%$ with a cost of $£ 2,000$ per installed $\mathrm{kWh}$, and the battery cost is $40 \mathrm{p} / \mathrm{kWh}$.

In predicting the future long term horizons, the following inputs described in Table 2 were used. 
Table 2 The cost and efficiency figures used to predict the long term payback trend.

\begin{tabular}{llllll}
\hline Year & PV efficiency & PV cost $(\$ / \mathrm{kWh})$ & LED efficacy & LED capital cost per $1,000 \operatorname{lm}$ & Battery cost $(\$ /$ Wh $)$ \\
\hline 2005 & 12 & 3,830 & 35 & 40 & 0.63 \\
2010 & 14 & 2,250 & 56 & 18 & 0.45 \\
2015 & 16 & 1,660 & 150 & 7.5 & 0.35 \\
2020 & 18 & 1,330 & 175 & 3 & 0.3 \\
2025 & 20 & 1,080 & 200 & 2 & 0.27 \\
2030 & 21 & 1,000 & 200 & 1 & 0.25 \\
2040 & 21.5 & 830 & 200 & 1 & 0.24 \\
2050 & 22 & 750 & 200 & 1 & 0.24 \\
\hline
\end{tabular}

\section{Results and Discussion}

If there are no occupancy sensors, then there is an average daily PV excess for six months of the year, as can be seen by the red line in Fig. 2 (when the red line is above the horizontal axis there is a net PV excess, conversely below horizontal axis denotes grid use), and the battery size is determined by the maximum daily deficit PV energy in comparison to the load (green line), averaged over the whole year. It was found to be $-1,650 \mathrm{Wh}$, indeed shows that, there was little variation in maximum daily deficit each month. Allowing for a factor of 1.5 to consider the non-ideal battery behaviour, this also resulted in a battery size exceeding $400 \mathrm{Ah}$, which (as of 2013) is beyond the range of typical devices on the market.

In the presence of occupancy sensors to light only $50 \%$ of the floor space, a more interesting picture emerges (Fig.3) There is an average daily PV excess for eight months of the year, the annual average maximum daily deficit, is around $780 \mathrm{Wh}$, and the battery size is just under $200 \mathrm{Ah}$, which (as of 2013) is now well within the range of commercial devices on the market. It seems that by reducing the required lighting power, in this case, by reducing the required floor area to be lit, we correspondingly reduce the required battery size.

Fig. 4 explores how the future projections of PV and LED performance determine the payback period: As the LED luminous efficacy improves from $60 \mathrm{~lm} / \mathrm{W}$ to $120 \mathrm{~lm} / \mathrm{W}$, the payback is expected to reduce by around three years. In comparison, if the PV cost per

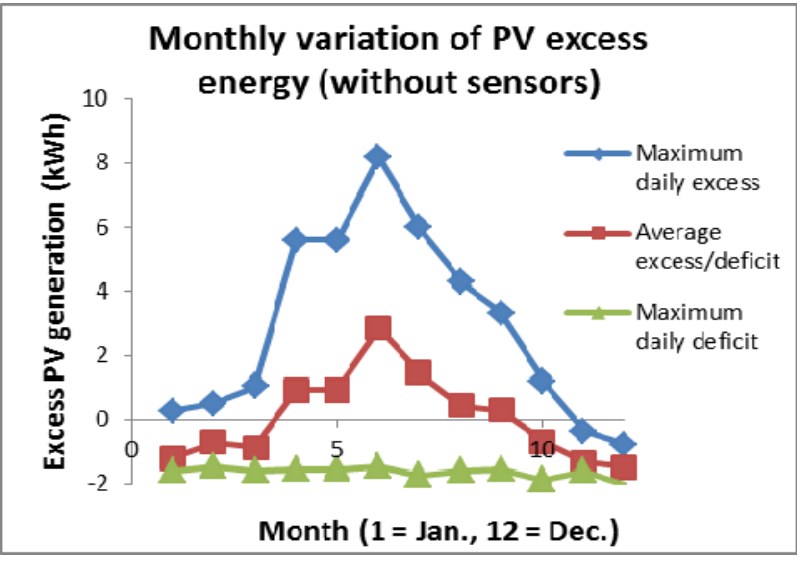

Fig. 2 The monthly difference between the generated PV energy and load use if there are no occupancy sensors.

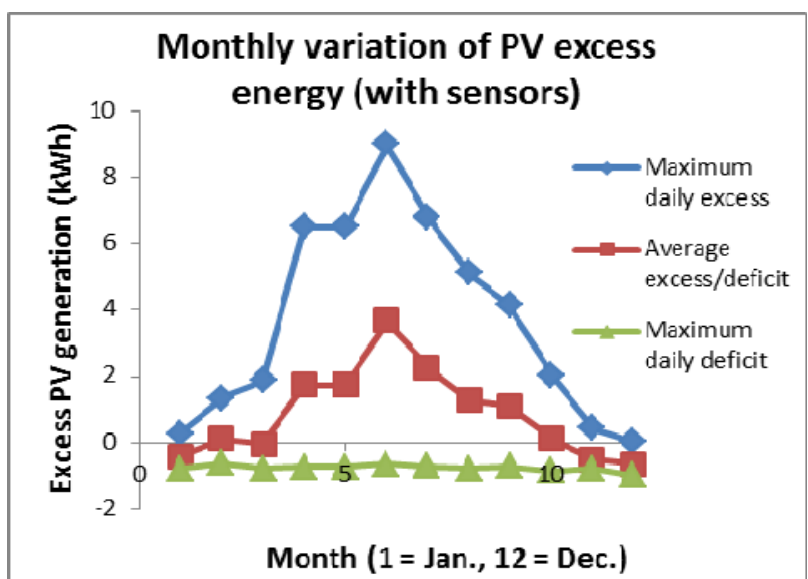

Fig. 3 The monthly difference between the generated PV energy and load use when there are room occupancy sensors.

installed $\mathrm{kW}$ were to half, then so would the payback period. Indeed, once the PV cost drops to $£ 500$ per $\mathrm{kW}$, then the payback period is of the order of a few years-similar to that contributed by the LED luminaires themselves.

The effect of solar tracking has not been considered 


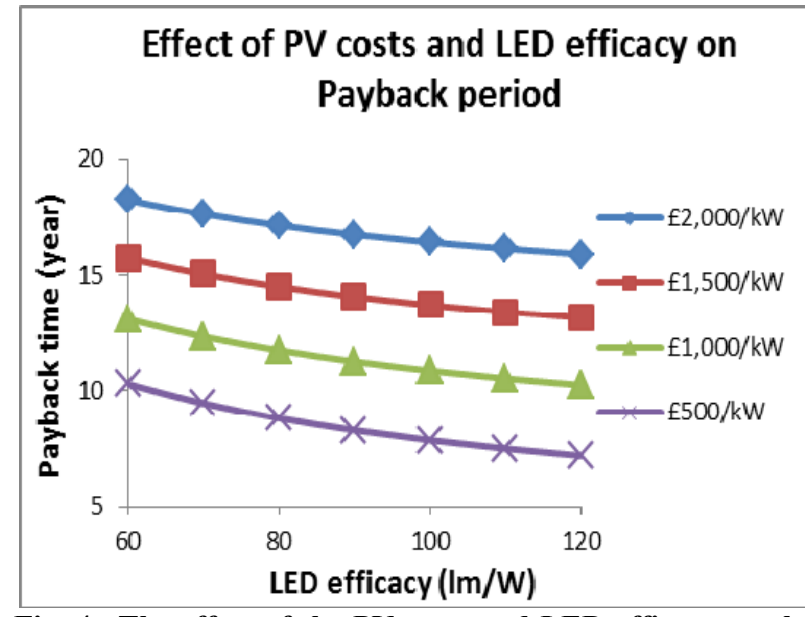

Fig. 4 The effect of the PV costs and LED efficacy on the payback period.

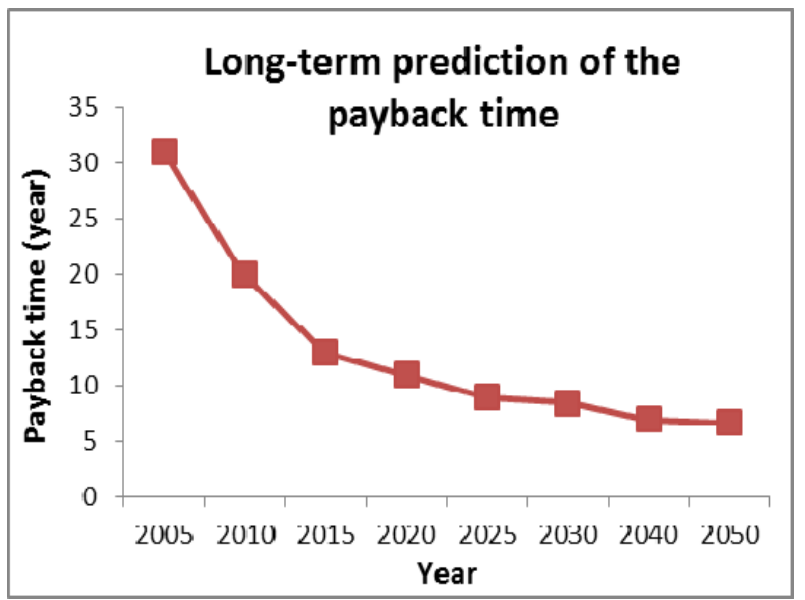

Fig. 5 Long-term prediction of the payback time.

here, but work by the authors is currently ongoing, and it is expected that, this would increase the annual PV output by an extra 30\%-40\%. The long-term behavior up to 2050 (Fig. 5) showed that, there is a rapid reduction in the payback from 30 years to 10 years up to 2020, and then there is only a slight reduction in the payback of 7 years up to 2050. As can be inferred from Table 2, the PV and LED costs drop quite rapidly, but the battery cost reduction is more gradual. Thus it is expected that, by 2020 , the payback has shortened to encourage a large-scale uptake of the PV-Battery-LED systems.

\section{Summary}

The economic viability of PV-LED systems for interior lighting of residential and other small buildings have been investigated. It has been shown that, for the typical system sizing and costs (as of 2013), the energy storage requirements are beyond the range of current commercial batteries. However, if it is desired that $50 \%$ less floor area needs to be lit for the given PV roof area, then commercial batteries of around $200 \mathrm{Ah}$ can accommodate this storage requirement. Also, at present, the payback period is dominated by the high PV cost, and this needs to reduce by at least half before its contribution is comparable to that of the battery and LED luminaires. Nevertheless, during the next few years, costs and efficiencies are set to improve significantly, and we should begin to see large scale uptake of this technology. Further, this solar-battery system can be used to power other DC applications, e.g., solar panels on garages powering electric cars.

\section{Acknowledgments}

The authors would like to acknowledge the discussions with numerous other colleagues at the Welsh School of Architecture, and for the availability of a research grant from the Low Carbon Built Environment Project, supported by the European Regional Development Fund through the Welsh Government.

\section{References}

[1] Zhu, D. 2012. "High-Efficiency InGaN/GaN Quantum Well Structures on Large Area Silicon Substrates." Physica Status Solidi (A) Applications and Materials Science 209 (1): 13-6.

[2] Humphreys, C. J. 2008. "Solid-State Lighting." MRS Bull 33 (04): 459-70.

[3] Shailesh, K. R., and Raikar, T. S. 2010. "Application of RELUX Software in Simulation and Analysis of Energy Efficient Lighting Scheme." International Journal of Computer Applications 9 (7): 24-35.

[4] Biber, C. 2008. LED Light Emission as a Function of Thermal Conditions. Portland: Biber Thermal Design Ltd.

[5] Parry, J. 2011. "Thermal Simulation Simplifies LED Luminaire Development.” Mentor Graphics-White Paper.

[6] Dong, T., and Narendran, N. 2009. "Understanding Heat Transfer Mechanisms in Recessed LED Luminaires." 
Presented at the Ninth International Conference on Solid State Lighting, San Diego, USA.

[7] Jou, J. H. 2009. "Sunlight-Style Color-Temperature Tunable Organic Light-Emitting Diode." Applied Physics Letters 95 (1): 013307-013307-3.

[8] Liu, G. 2012. "Techno-Economic Simulation and Optimization of Residential Grid-Connected PV System for the Queensland Climate." Renewable Energy 45 (September): 146-55.

[9] Liu, G. 2012. "Simulation and Optimization of Residential Grid-Connected PV System in Queensland, Australia." Advanced Materials Research 347-353 (October): 715-24.

[10] Sastry, O. S. 2010. "Development of White LED Based PV Lighting Systems." Solar Energy Materials and Solar Cells 94 (9): 1430-3.

[11] Boeke, U., Wendt, M., and Yseboodt. L. 2011. "Combined Solar and AC Mains Powered LED Lighting System." In Proceedings of the 2011 14th European Conference on Power Electronics and Applications, 1-8.

[12] Panguloori, R., Mishra, P., and Boeke, U. 2011. "Economic Viability Improvement of Solar Powered Indian Rural Banks through DC Grids." In Proceedings of the 2011 Annual IEEE India Conference, 1-4.

[13] Patel, A. R. 2011. "Modeling and Simulation of Photovoltaic Based LED Lighting System." World Academy of Science, Engineering and Technology 73 (March): 647-51.

[14] Pode, R. 2010. "Solution to Enhance the Acceptability of
Solar-Powered LED Lighting Technology." Renewable and Sustainable Energy Reviews 14 (3): 1096-103.

[15] Leadbetter, J., and Swan, L. G. 2012. "Selection of Battery Technology to Support Grid-Integrated Renewable Electricity." Journal of Power Sources 216 (October): 376-86.

[16] Braun, M. 2009. "Photovoltaic Self-Consumption in Germany Using Lithium-Ion Storage to Increase Self-Consumed Photovoltaic Energy." Presented at the 24th European Photovoltaic Solar Energy Conference and Exhibition, Hamburg, Germany.

[17] Albright, G., Edie, J., and Al-Hallaj, S. 2012. "A Comparison of Lead Acid to Lithium-Ion in Stationary Storage Applications." Alternative Energy Emagazine Industry.

[18] Esram, T., and Chapman, P. L. 2007. "Comparison of Photovoltaic Array Maximum Power Point Tracking Techniques." IEEE Transactions on Energy Conversion 22 (2): 439-49.

[19] Huang, B. J. 2010. "Development of High-Performance Solar LED Lighting System." Energy Conversion and Management 51 (8): 1669-75.

[20] Kelly, N. A., and Gibson, T. L. 2009. "Improved Photovoltaic Energy Output for Cloudy Conditions with a Solar Tracking System.” Solar Energy 83 (11): 2092-102.

[21] Sarnobat, P., and Lannon, S. 2013. "Simulation of PV-Battery-LED Systems in Office Buildings." In Proceedings of the 13th Conference of International Building Performance Simulation Association (at press). 